\title{
A Study of the Consolidation Method with Albumin to Obtain Porous $\beta$-TCP Ceramics
}

\author{
Christiane Ribeiro*, José Carlos Bressiani, Ana Helena de Almeida Bressiani \\ Instituto de Pesquisas Energéticas e Nucleares - IPEN, \\ Centro de Ciência e Tecnologia de Materiais - CCTM, \\ Av. Prof. Lineu Prestes, 2242, Cidade Universitária, 05508-000 São Paulo - SP, Brazil
}

Received: March 21, 2007; Revised: August 23, 2007

\begin{abstract}
In many 'in-vivo' and 'in-vitro' studies, the behavior of calcium phosphate ceramics like $\beta$ - tricalcium phosphate in biological environments has been reported to be predictive and positive. In terms of bone tissue growth, these ceramics are attractive biomaterials due to their porous microstructures. To obtain biomaterial quality ceramics, in this investigation $\beta$ - TCP porous ceramics were prepared by a special consolidation method with albumin as a foam generating agent. This technique enables a variety of formats with complex geometries to be prepared. To obtain porous samples using albumin, heat had to be introduced into the system during the consolidation stage. After consolidation, the samples were sintered at $1250{ }^{\circ} \mathrm{C}$ for 30 minutes and characterized using X ray diffractometry, scanning electron microscopy and mercury porosimetry. The foams that were obtained by this method exhibited spherical and interconnected pores, characteristics desirable in biomedical implants.
\end{abstract}

Keywords: calcium phosphate, porous material, direct consolidation, albumin

\section{Introduction}

The potential of porous biomaterials for applications in the medical, engineering and pharmaceutical fields has been widely reported ${ }^{1-3}$. Various processing techniques have contributed towards the development of porous biomaterials. Porous calcium phosphate ceramics such as $\beta$-TCP, obtained by foam consolidation, have features that are ideal for use as bone implants and scaffolds ${ }^{2,3}$. These ceramics exhibit interesting properties such as biocompatibility, osteoconduction and pore configuration (size, morphology and distribution). The concept of porous materials, from the biocompatibility point of view, is based on the pore dimensions being different from those in ceramics produced for use in the field of chemistry. According to IUPAC ${ }^{4}$ sub-committee for characterization of porous solids, macroporous materials have pores larger than 50 $\mathrm{nm}$. However, for it to be used as a biomaterial, the pores should have Harvesian diameters in the range of $50-250 \mu \mathrm{m}^{5}$.

Porosity is an essential requirement for adequate bone-implant integration. Cell proliferation in scaffolds used in tissue engineering is one of the main properties and this is possible due to the interconnected pores in the matrix ${ }^{2}$.

One of the techniques that have been widely used to manufacture porous ceramics is colloidal processing. This wet processing technique enables a variety of formats with complex geometries to be obtained ${ }^{6}$. In this technique, aqueous ceramic suspensions are prepared with albumin as a special agent with dual functions, gel formation and foaming ${ }^{7}$. In the other techniques to obtain foams, like the traditional gel casting of foams, the neurotoxic nature of the monomers is a limiting factor ${ }^{6}$. Hence, this new methodology to produce porous biomaterials is considered to be promising as it does not pose any danger with respect to handling of additives, it does not require controlled atmospheres for foam consolidation and the pores are spherical ${ }^{7}$.

In this innovative consolidation process with albumin, heat is introduced to the system which leads to gel formation. To obtain porous ceramics, the process conditions were optimized and this was done by conducting parallel studies. Integrated treatment of the properties of the material, adapted to this methodology, permitted improved control and reproducible samples.

This paper presents the process to manufacture $\beta$-tricalcium phosphate ceramic foams using the direct consolidation method with ovalbumin. This is an albumin from egg white, supplied by Nutraceutica.

\section{Materials and Methods}

To prepare the suspensions, $69 \mathrm{wt}$. (\%) of solids in the form of $\beta$-TCP (Fluka) and ovalbumin (Schettert) powder were used. To obtain the foams, $0.6 \mathrm{mg} . \mathrm{m}^{-2}$ of dispersant (Dispex A 40 from CIBA), a nonionic surfactant (Genaminox - Clariant) and 0.08 wt. (\%) of amine dimetil alkyl oxide were added to the $\beta$-TCP aqueous suspension. Albumin was added (5, 6 and $7 \mathrm{wt}$. (\%)) to the ceramic suspensions to form the gel and stabilize the foam. Albumin is considered as a solid in this methodology and it competes with the ceramic in the dispersion stage to generate pseudoplastic suspensions.

To study gel formation, oscillatory tests were carried out at a constant frequency and stress of $1 \mathrm{~Hz}$ and $1 \mathrm{~Pa}$ respectively. Measurements were taken after 30 seconds. In the tests, aqueous suspensions containing different concentrations of albumin $(5,6$, 7 wt. (\%)) were used. The parallel plate measurement system was used to determine the variables $\mathrm{G}^{\prime}$ (storage or elastic modulus) and $\mathrm{G}^{\prime \prime}$ (loss or viscous modulus), as a function of temperature $\left(35-80{ }^{\circ} \mathrm{C}\right.$ ).

In this methodology, the measurements were carried out as a function of temperature $\mathrm{T}\left({ }^{\circ} \mathrm{C}\right)$, as this parameter influences solidification of the suspension and is a variable that directly affects albumin gel formation and protein denaturation. The foam that was formed was held in an oven at $60{ }^{\circ} \mathrm{C}$ for 12 hours to complete gel formation. This temperature was chosen based on rheological studies 
that were carried out to determine the gel point. Subsequently the specimens were heat treated at $600{ }^{\circ} \mathrm{C}$ for 2 hours and a heating rate of $3{ }^{\circ} \mathrm{C} / \mathrm{min}$ was used to ensure total degradation of the organic phase. The specimens were sintered at $1250{ }^{\circ} \mathrm{C}$ for 30 minutes in air and a heating rate of $5^{\circ} \mathrm{C} / \mathrm{min}$ was used. The starting materials and the foams were analyzed in a Bruker - AXS Model D8 X ray diffractometer. The measurements were carried out at room temperature in the $2 \theta$ range $10^{\circ}-60^{\circ}$. Pore size distribution was determined with a Micromeritics - Autopore III mercury porosimeter. The microstructure and pore geometry were studied in a Philips XL 30 scanning electron microscope.

\section{Results and Discussion}

It is important to determine the behavior of the consolidating agent before obtaining the foam. The consolidation stage can be better interpreted by evaluating the rheological characteristics that play a dominant role during transition of the liquid suspension to a solid. The sol to gel transition can be monitored by measuring the elastic modulus (storage modulus - G' and the loss or viscous modulus - G') at a certain frequency as a function of time and/or temperature. The elastic component $\left(G^{\prime}\right)$ indicates the amount of applied stress that is temporarily stored and instantaneously recovered, and the viscous component (G”) is related to the energy used to irreversibly transfer heat to start the viscous flow ${ }^{8}$.

The rheograms in Figures 1-3 show the viscous and elastic response behavior of the different albumin suspensions $(5,6$, 7 wt. (\%)) as a function of temperature. These graphs show the gel formation points of the different specimens (intersections of $G^{\prime}$ and G" curves).

In the early stages, the rheological behavior of the suspensions is characterized by a loss modulus (G') higher than the storage modulus (G'), defining thus the viscous behavior of these systems. (G'> G'). Physically, the suspension becomes more elastic as its capacity to dissipate energy during deformation increases. With increasing temperature, the elastic component predominates over the viscous component, a behavior characteristic of the gel (G'> G'). The marked increase of G', beyond the intersection point of the two (G' and G') could be due to rapid formation of junction zones between chains that form the gel network ${ }^{9}$. In published literature, one of the criteria used to determine the gel point is the intersection of the G' and G" curves ${ }^{10,11}$.

The suspensions containing: 5, 6 and $7 \mathrm{wt}$. (\%) of albumin had gel points at equivalent temperatures to 65,69 and $75^{\circ} \mathrm{C}$ respectively. It

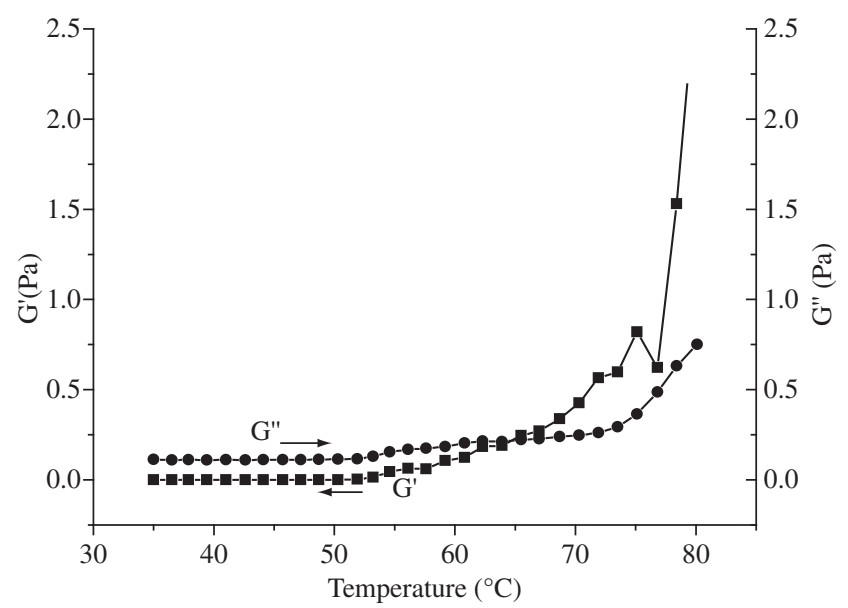

Figure 1. Rheograms showing the elastic (G') and viscous (G') moduli of the suspension with $5 \mathrm{wt}$. (\%) albumin, as a function of temperature. can be seen that with increasing albumin content, there is an increase in temperature for gel formation.

At the molecular level, the optimum temperature for gel formation corresponds to the maximum in cooperation of the hydrophobic interactions and hydrogen bond formation. Secondary bonds are affected in a different manner by temperature change. While the hydrogen bonds are stabilized by decreasing temperature, the hydrophobic bonds form at high temperatures ${ }^{11}$. At high temperatures, the gel point is normally characterized by a weak three-dimensional network, due to the limited contribution of the hydrogen bonds. In this case, gel formation takes place quickly due to the predominant contribution of hydrophobic bonds ${ }^{11}$. Slow drying ensures stronger structures, and these structures are obtained preferentially by cooperation between hydrogen bonds and the reduced amount of hydrophobic interactions. This can be achieved by consolidating the foam at $60{ }^{\circ} \mathrm{C}$. In the case of the $6 \mathrm{wt}$. (\%) albumin suspension, a constant $\mathrm{G}^{\prime}$ value close to $0.86 \mathrm{~Pa}$ around $78{ }^{\circ} \mathrm{C}$ is observed. This probably indicates the end of the gel formation reaction. At temperatures close to $80{ }^{\circ} \mathrm{C}$, a decrease in G' has been observed. These oscillations in behavior can be attributed to destructuring of the material, which at these temperatures was probably being stressed beyond the elastic regime or to the existence of a structure that resulted from some pre-aggregation of protein particles ${ }^{11}$.

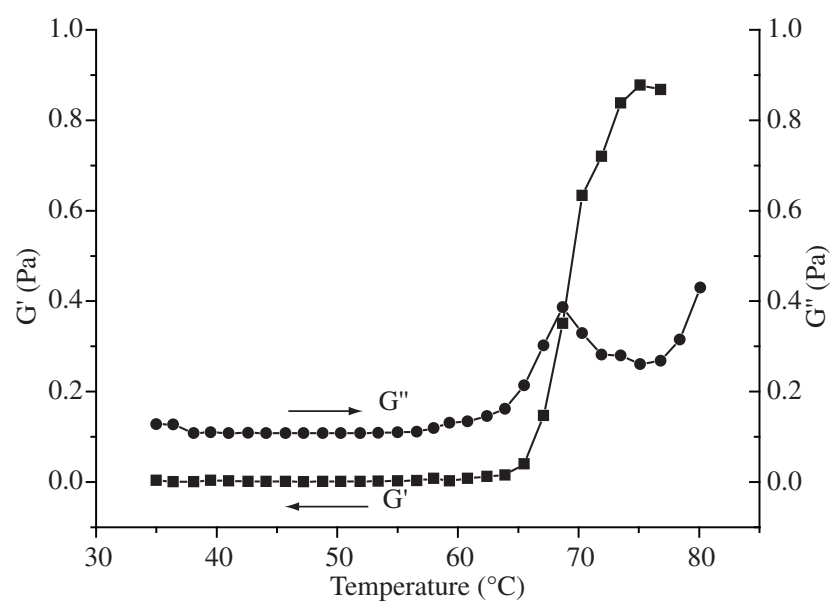

Figure 2. Rheograms showing the elastic (G') and viscous (G') moduli of the suspension with $6 \mathrm{wt}$. (\%) albumin, as a function of temperature.

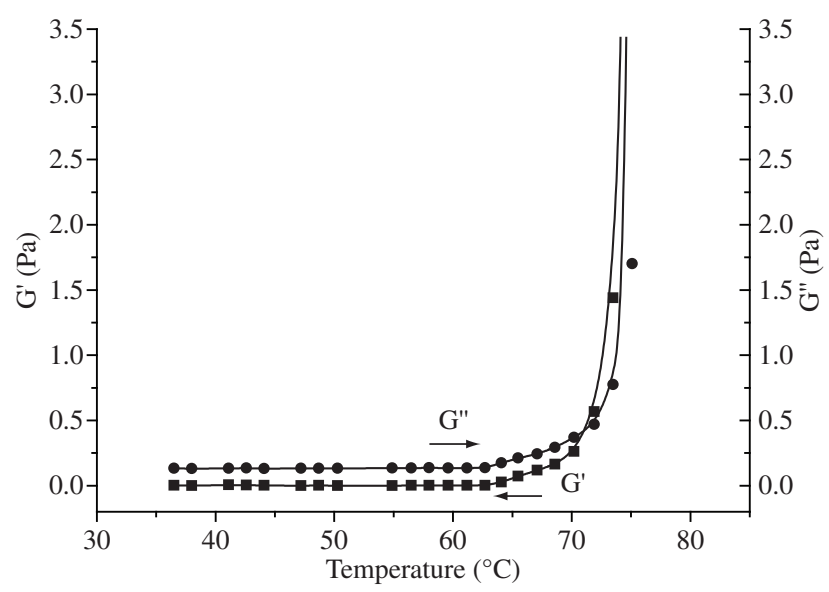

Figure 3. Rheograms showing the elastic (G') and viscous (G') moduli of the suspension with $7 \mathrm{wt}$. (\%) albumin, as a function of temperature. 
During the consolidation stage, from albumin, the role of temperature is important. In this system, the formation of a gel structure occurs naturally. This is driven by absorption of heat from an external source. Heat absorption happens in the direction surface to bulk in the suspension. Consequently, there are differences in porosity between the bulk and the contact surfaces (solid/air, solid/ mold wall). The films on the contact surfaces are easily removed during the preparation stage, resulting in specimens with more homogeneous porosity.

Temperature increase could result in premature collapse of bubbles. This effect can be compensated by increasing the viscosity of the suspension with albumin additions. The albumin stabilizes perturbations in the film between bubbles. Gas diffusion between bubbles, due to the Laplace pressure gradient, determines spreading of the liquid through the film. This is inhibited by the insoluble layer of adsorbed albumin. Consequently, bubble elasticity increases and results in a more stable film. This mechanism retards bubble collapse, an effect known as Ostwald ripening ${ }^{7}$. When the suspension was held in the oven during the consolidation stage, foam was observed close to the mold wall.

This process is not affected by the presence of oxygen and it also does not require a controlled atmosphere to inhibit foam consolidation, compared to the traditional method of foam gel casting in which this is an important parameter ${ }^{6}$.

Figure 4 shows the $\mathrm{X}$ ray diffraction profiles of the samples in the different states: the starting material, the sintered ceramic and the sintered foam obtained with the higher albumin content (7 wt. (\%)). The diffractograms were studied using the JCPDS 9169 card.

Peaks related to secondary phases in the starting material or other phases in the sintered TCP were not observed. The presence of albumin as a foam constituent did not result in any new phase and the diffractogram was identical to that of the specimen sintered without albumin.

The porosity results determined using a mercury porosimeter are shown in Figure 5 and porosity is expressed as volume of intruded mercury as a function of pore diameter.

A direct relationship between the amount of albumin and specimen pore interconnection can be seen. Increase in albumin concentration in the suspension resulted in a large number of small interconnections in the sample. This effect is related to the exponential increase in viscosity in the presence of albumin, due to its tendency

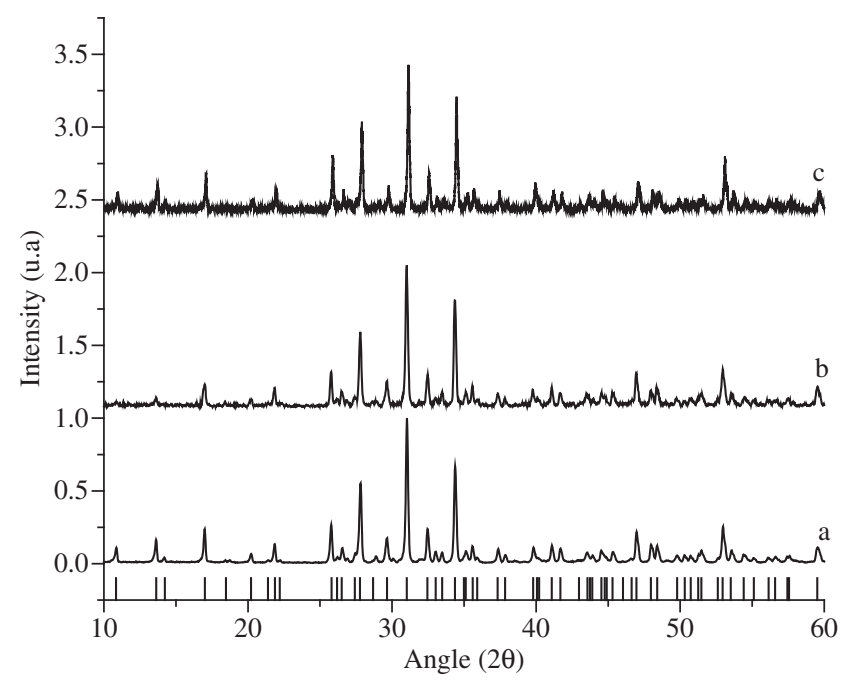

Figure 4. X ray diffractograms of the different specimens: a) starting powder; b) sintered ceramic at $1250{ }^{\circ} \mathrm{C} / 30 \mathrm{~min}$; c) sintered foam at $1250{ }^{\circ} \mathrm{C} / 30 \mathrm{~min}$. to absorb water. This characteristic confers increased resistance to the suspension to form foam and results in reduced porosity.

The specimens revealed a narrow interconnection distribution in the range 1.0-5.0 $\mu \mathrm{m}$ and a wide distribution of interconnection in the range $30-200 \mu \mathrm{m}$. Even by varying the albumin content, the pore distribution was the same, as observed in the other specimens. The small pore fraction seen in the specimens and observed in the micrographs of Figure 6 contribute directly towards inter-pore connectivity. Large pore size was not measure by mercury porosimetry because this technique shows the diameter of the interconnections. Interconnected pores are an important feature and this has been shown, in various studies, to contribute to and maintain bone tissue growth, by transport of nutrients and drainage of interstitial fluids ${ }^{1-3}$. Pores with dimensions close to $5 \mu \mathrm{m}$ can further facilitate ionic migration that happens initially between the surface of the implant and blood plasma, influencing favorably the cell absorption dynamics. These pores are also important in terms of capillarity and permeability of body fluids, which could contribute to dissolution of this ceramic ${ }^{1,3}$.

The micrographs shown in Figure 6 reveal that the technique is reproducible in terms of interconnected pores. The differences among the foams are evident in terms of the volume of total porosity (Table 1).

Among the different specimen fracture surfaces, no significant topographical differences were observed (Figure 6). Published literature reports that the surface topography and chemical composition of implants influence osteogenic cell response ${ }^{2}$.

The observed micropores may play an important role in cell activation processes at the materials surface. This type of porosity is morphologically functional by contributing to surface roughness. The roughness induces more bone formation compared to smooth surfaces, due to increased anchoring of fine osteoblastic type of cells ${ }^{1,2}$. The macropores in these specimens provide paths for bone tissue growth, as these easily penetrate the pores and establish the osteoconduction process. The filling of these pores with new bone tissue brings about strong interlaced bone-implant and confers increased strength to the implant.

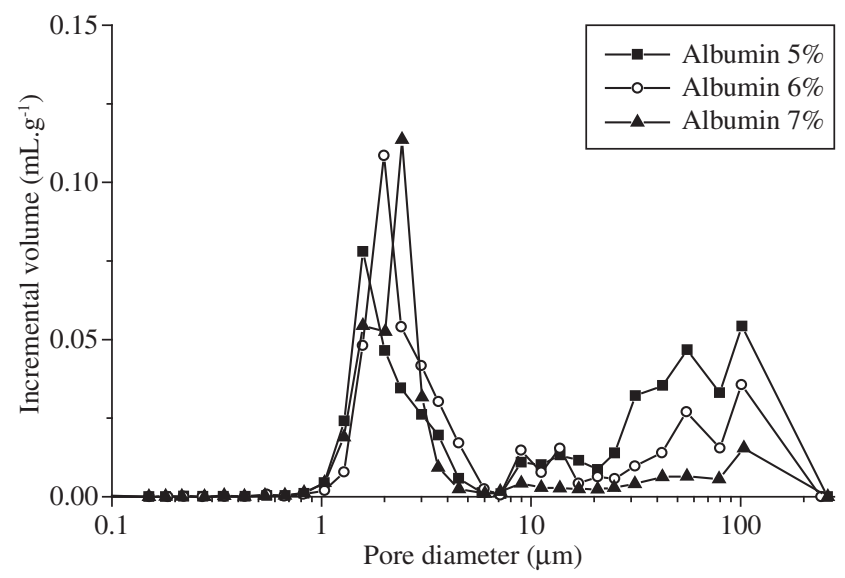

Figure 5. Curves of pore size distribution frequency as a function of volume intruded mercury.

Table 1. Total porosity values of foams obtained by mercury porosimetry technique.

\begin{tabular}{cc}
\hline Samples & Total porosity (volume) \\
\hline TCP 5 & $57.9 \%$ \\
TCP 6 & $54.5 \%$ \\
TCP 7 & $50.8 \%$ \\
\hline
\end{tabular}



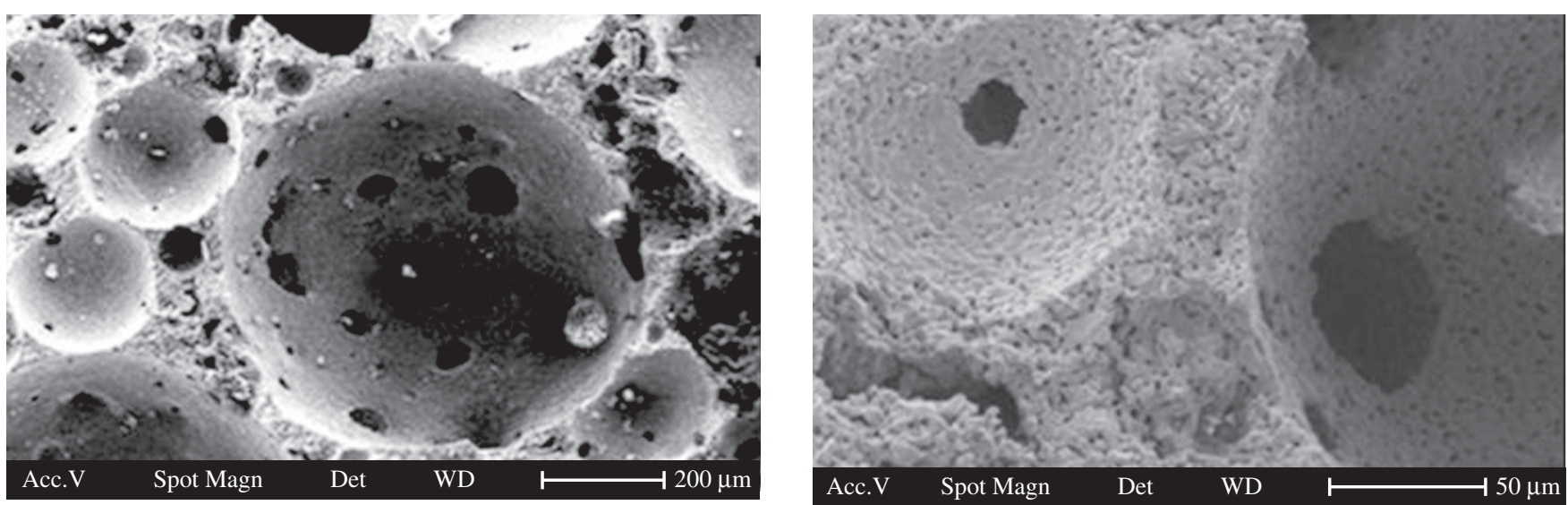

(a)
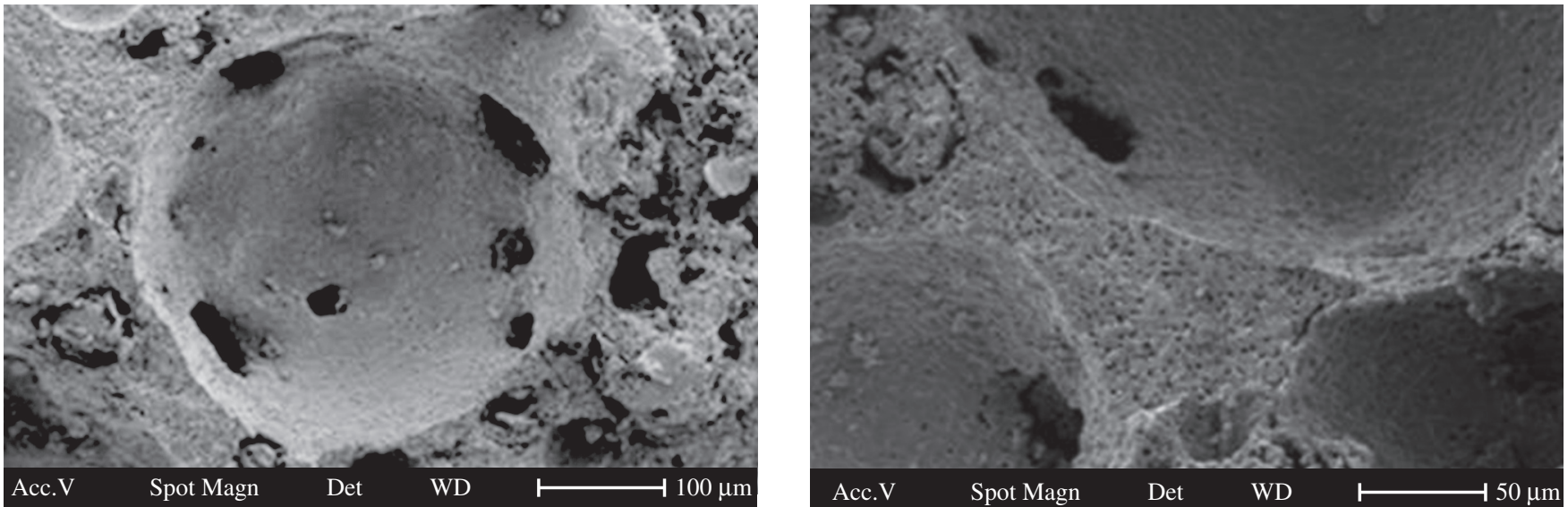

(b)

Figure 6. Micrographs of fractured surfaces of specimens obtained by the direct consolidation process using albumin. a) $\beta$-TCP $6 \%$ albumin; and b) $\beta$-TCP $5 \%$ albumin.

\section{Conclusions}

The foaming action, along with the consolidation effect of this albumin methodology is the main attribute of this technique and this improves porous ceramic processing.

The suspensions that were obtained had adequate stability for foam solidification, due to slow drainage brought about by high surface viscosity.

The different albumin suspensions had gel points between 60$70{ }^{\circ} \mathrm{C}$. In the three suspensions that were studied, increase in storage modulus $\left(\mathrm{G}^{\prime}\right)$ was observed after the start of gel formation.

The presence of albumin did not alter the crystalline phases in the sintered ceramic foams. It helped to form micro and macro pores with characteristics such as size, spherecity and pore interconnectivity, features that are of interest for its use as a biomaterial.

\section{Acknowledgments}

The authors are grateful to CNPq and FAPESP for financial support and to Schettert Nutraceutic for supplying the albumin used in this investigation.

\section{References}

1. Ratner BD, Hoffman AS, Schoen FJ, Lemons JE. Biomaterials Science. An introduction to Materials in Medicine. Academic press, London, UK, 2002.

2. Liebschner MAK, Wettergreen MA. Topics in tissue Engineering; Ashammakhi $\varepsilon$ Ferretti, New York, USA; 2003.
3. Yaszemski MJ, Payne RG, Hayes WC, Langer R, Mikos AG. Evolution of bone transplantation: molecular, cellular and tissue strategies to engineer human bone. Biomaterials. 1996; 17(2):175-85.

4. Lastoskie C, Gubbins KEJ, Quirkeft N. Pore Size Distribution Analysis of Microporous Carbons: A Density Functional Theory Approach. J. Phys. Chem. 1993; 97:4786-4796.

5. Kawachi EY, Bertran CA, Reis R, Alves OL. Biocerâmicas: tendências e perspectivas de. uma área interdisciplinar. Quím. Nova. 2000; 23(4):518-522. São Paulo

6. Ortega FS, Valenzuela FAO, Scuracchio CH, Pandolfelli VC. Alternative gelling agents for the gelcasting of ceramic foams. Journal of the European Ceramic Society. 2003; 23(1):75-80.

7. Dhara S, Bhargava P. Egg white as an Environmentally friendly low-cost binder for gelcasting of ceramics. J. Am. Ceram. Soc. 2001; 84(12):3048-3050.

8. Anjos RD, Salomão R, Pandolfelli VC. Novas técnicas de reometria aplicadas a suspensões cerâmicas. Cerâmica. 2005; 51(318):173-179.

9. Weijers M, Sagis LMC, Veerman C, Sperber B, Van Der Linden E. Rheology and structure of ovalbumin gels at low $\mathrm{pH}$ and low ionic strength. Food Hydrocolloids. 2002; 16(3):269-276.

10. Laza JM, Julian CA, Larrauri E, Rodriguez M, Leon LM. Thermal scanning rheometer analysis of curing kinetic of an epoxy resin: An amine as curing agent. Polymer. 1999; 40(1):35-45.

11. Weijers M, Van De Velde F, Stijnman A, Visschers RW. Structure and rheological properties of acid-induced egg white protein gels. Food Hydrocolloids. 2006; 20(2-3):146-159. 